\title{
C-arm Guided Minimally Invasive Percutaneous Fixation Technique of Mandibular Angle and Ramus Fractures- a Prospective Clinical Study at a Tertiary Care Centre of Odisha, India
}

\author{
Sourav Kumar Rout ${ }^{1}$, Subrat Kumar Jena ${ }^{2}$
}

\author{
Author Info: \\ 'Department of Cranio \\ Maxillofacial surgery, Ashwini \\ Hospital, Cuttack, Odisha, \\ India. \\ ${ }^{2}$ Department of Plastic, Hand \\ and Microsurgery and Burns, \\ Ashwini Hospital, Cuttack, \\ Odisha, India
}

\section{Corresponding Author:}

Authors Dr Sourav Kumar Rout, Department of Cranio Maxillofacial surgery, Ashwini Hospital,

Cuttack, Odisha, India.

Mobile: +919937135861

Email: saurav06123@gmail.com

\begin{abstract}
Background: Rigid internal fixation of displaced mandibular angle and ramus fractures often poses a unique challenge to oral and maxillofacial surgeons. Various methods have been published to provide a safe and secure gateway for these circumstances. Intra-oral approach supplemented by a limited percutaneous method of fixation offers a distinct advantage of rigid fixation, reducing the known morbidity of using the sole internal as well as external techniques. The objective was to describe a minimally invasive technique for the mandibular angle and ramus fractures using the combined intraoral and extra-oral approach.
\end{abstract}

Methods: This study was conducted on ten patients with mandibular angle or ramus fractures. All patients underwent open reduction and internal fixation. The intra-oral incision was used for visualization and reduction of fractures, and supplemental percutaneous stab incision was utilized to create a path for insertion of the handheld battery-operated microdrill shaft and screwdriver to permit screws fixation perpendicular to the plates.

Results: This combined technique depicted minimal or no soft tissue infections, wound dehiscence, occlusal disturbances, or seventh cranial nerve paralysis. The mean surgical duration was 41.5 minutes. No patient had an visible scar marks, which would require further intervention.

Conclusion: The described minimally invasive combined percutaneous and intraoral approach for mandibular angle, and ramus fracture provides a satisfactory alternative which could be safely applied to provide rigid fixation of these fractures with minimal damage to vital structures.

Keywords: C-arm guided, Fracture, Minimally invasive, Percutaneous fixation

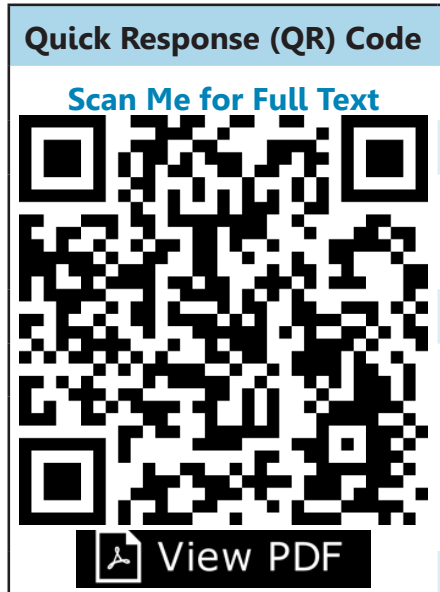

\section{Article Info}

Received: 12 June 2020; Accepted: 7 Aug 2020; Published Online: 8 Aug 2020

How to cite this article in Vancouver Style?

Rout SK, Jena SK. C-arm Guided Minimally Invasive Percutaneous Fixation Technique of Mandibular Angle and Ramus Fractures - a Prospective Clinical Study at a Tertiary Care Center of Odisha, India. Europasian J Med Sci. 2020; 2(2):10-16. https://doi.org/10.46405/ejms.v2i2.53

Conflict of Interest: None Declared;

Source of Support: Nil

Copyright: ( $\odot 2020$ by author(s). This is an open access article distributed under the terms of the Creative Commons Attribution International License 4.0 (http://creativecommons.org/licenses/ by/4.0/) which permits unrestricted use, distribution, and reproduction in any medium, provided the original work is properly cited.

\section{Publisher's Note}

The Europasian Journal of Medical Sciences (EJMS) (www.europasianjournals.org) is an official Journal of Nirvana Psychosocial Care Center \& Ressearch Institute (www.nirvanapscc.com). The Journal as well as publisher remain neutral with regards to any jurisdictional claims in any published articles, its contents and the institutional affiliations of the authors. 


\section{INTRODUCTION}

Mandibular fractures are one of the most common fractures in the facial skeleton due to its vulnerable location and lack of support. ${ }^{1}$ Optimum management of these fractures is essential for the complex function of the jaws in addition to its aesthetic importance. Fractures of the symphysis, para-symphyseal area and condyle are caused by road traffic accidents or fall with an impact on the chin. In contrast, a lateral traumatic force on mandible can cause fracture of angle, body, ramus and contralateral condylar. ${ }^{2}$ The angle is one of the most common locations of the mandibular fractures from blunt trauma force to the face accounting for $23 \%$ to $42 \%$ of all mandibular fractures. ${ }^{3}$

Treatment of mandibular angle fracture brings a fair share of challenges because of its association with the greater risk of complications such as infection, malunion, malocclusion, and seventh cranial nerve injury ranging from $0 \%$ to $14.7 \%$ in various studies. ${ }^{4,5}$ Various techniques have been described in the literature and practised to deal with these fractures such as intra-oral approach, external approach, combined intraoral with trans buccal approach or percutaneous approach.

This study aims to describe a minimally invasive technique for the mandibular angle and ramus fractures using the combined intraoral and extraoral approach under fluoroscopic guided images.

\section{MATERIALS AND METHODS}

This prospective study was conducted on ten patients who had the trauma-related mandibular angle and ramus fractures reporting to the department of craniomaxillofacial surgery at Ashwini Hospital, Cuttack, Odisha from February 2019 to January 2020.

\section{Inclusion criteria:}

All displaced/ un-displaced mandible angle and ramus fractures with or without occlusal disturbances were included in the study.

\section{Exclusion criteria:}

Panfacial fractures and Severely comminuted mandibular angle, body, condyle, symphysis fractures and severely ill patients or patients with multiple co-morbidities were excluded from study.

Since patients were usually victims of road traffic accidents or fall from a height, a thorough examination by the different members of the trauma team was mandated before posting the patient for surgery. After that, a secondary survey with systemic evaluation was carried out. Pre anaesthetic check-up for the patients requiring surgery was done.

All the patients signed informed consent before surgery, and ethical committee approval was obtained.

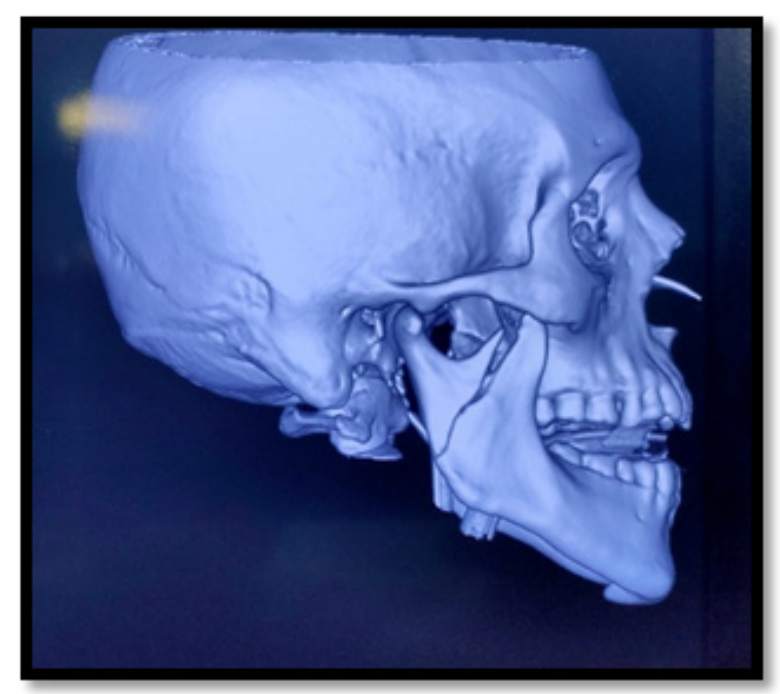

Figure 1 CT Scan image of fracture of ramus

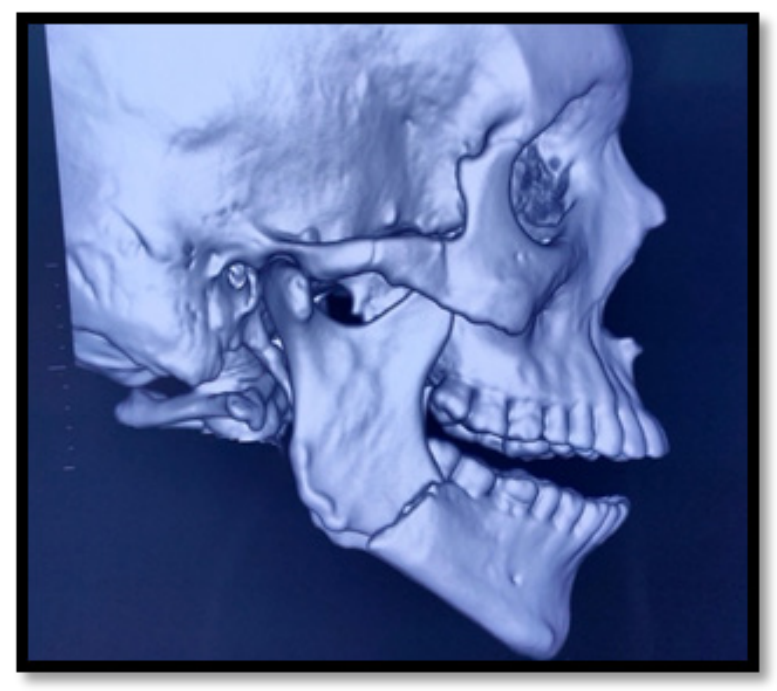

Figure 2. CT Scan image of fracture of angle

\section{The technique}

Under general anaesthesia with nasotracheal intubation or tracheostomy (when indicated), maxillomandibular fixation $(\mathrm{MMF})^{6}$ was done. $\mathrm{CT}$ images (Figure 1,2) were again checked and the fracture site was verified with clinical findings. After injecting a local anaesthetic solution with vasoconstrictor adrenaline 1:100000, an incision 
was placed on the external oblique ridge region with distal release incision extending higher up along the anterior border of ramus.

Subperiosteal dissection was done to achieve exposure till the fracture site was visible (Figure 3), fracture segment was reduced using a periosteal elevator intraorally, and the reduction was maintained by a K-wire introduced percutaneously passing through the fracture site. One or two mini plates of desired length were chosen and placed over the outer aspect of mandible spanning the fractured area, the selection criteria of single or double implant depended on the amount of fracture segments displacement. If the fracture segments were minimally displaced single titanium plate was used, if the fracture segments were severely displaced double implant were preferred. In this technique the fracture segments was reduced by placing $\mathrm{K}$ - wire first and then a stab incision was then placed extra orally in the mid-angle region overlying the fracture site. This position was determined using a K-wire passed through the skin and confirmed by a C-arm image to check the adequacy of reduction (Figure 9). After the stab wound through the skin, a tunnel was created by gently probing the soft cutaneous tissue and the masseter muscle by a straight pointed mosquitohaemostat. Then the trocar cannula was passed through this tunnel to emerge into the space created by the intra-oral dissection (Figure 4). The drill bit attached to handheld battery-powered handpiece (Synthes Colibri II) was passed through the trocar, and multiple drill holes were made through the holes of the plate into the bone (Figure 3). Mini screws were then introduced through the cannula perpendicular to the angle of mandible by

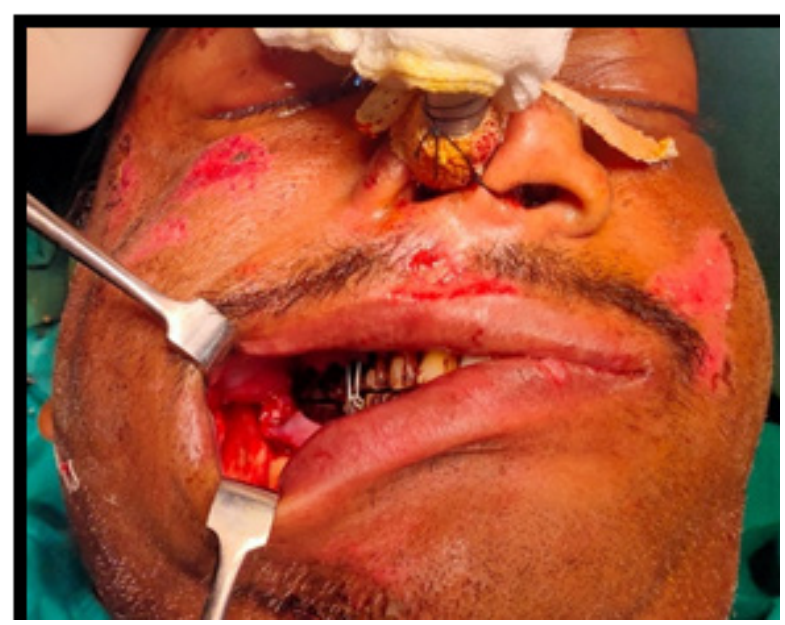

Figure 3 intra oral incision to expose fracture site

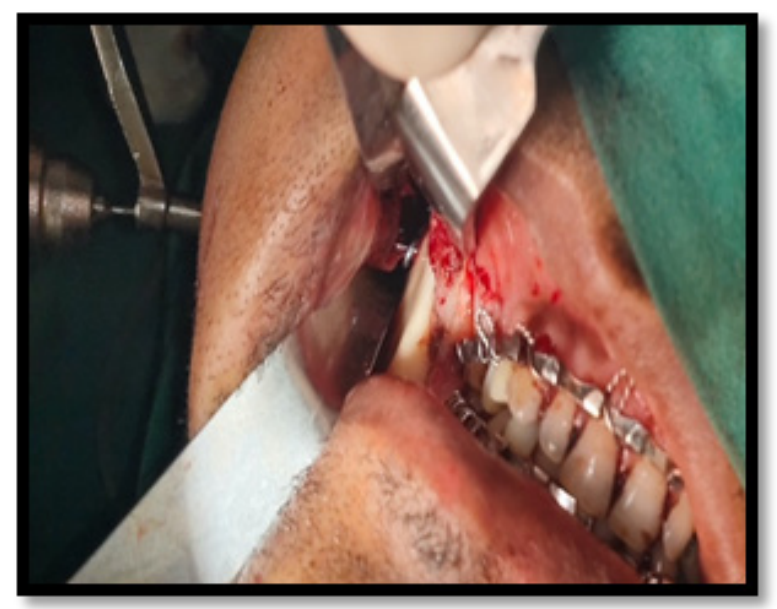

Figure 4 Percutaneous method of fixation using trocar

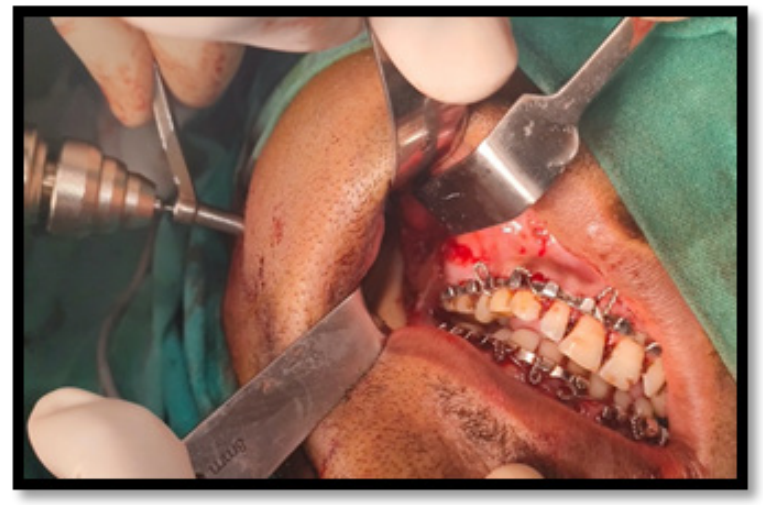

Figure 5 Percutaneous Rigid fixation of angle fracture with $2.4 \mathrm{~mm}$ titanium reconstruction plate

and screws

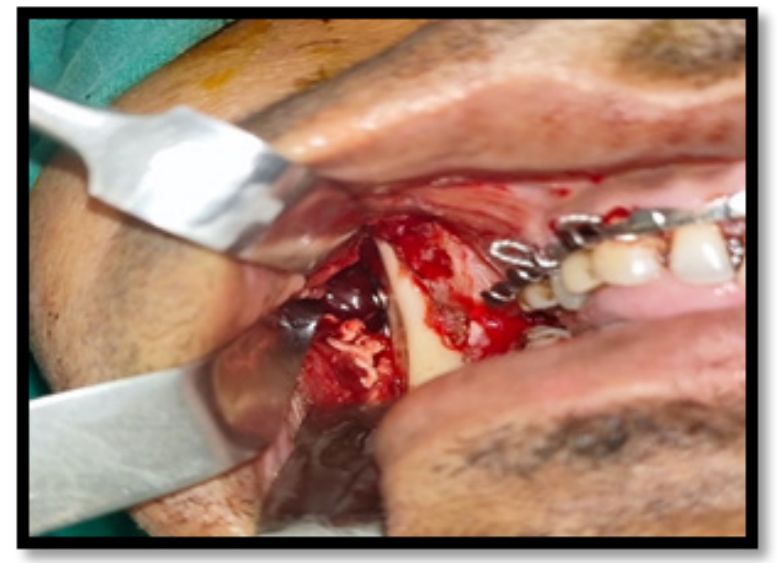

Figure 6 Percutaneous Rigid fixation of ramus fracture with $2.0 \mathrm{~mm}$ titanium mini plate and screws 
a self- locking screw driver. All the drill holes as well as screw fixation were done through the single stab wound by moving the trocar over the fracture site and the mini plate in the dissected space (Figure 5). Fracture fixation was done using 2.0 or $2.5-\mathrm{mm}$ diameter plates and screws and either 1 or 2 mini plates as required depending on the displacement of fracture segments (Figure 6).

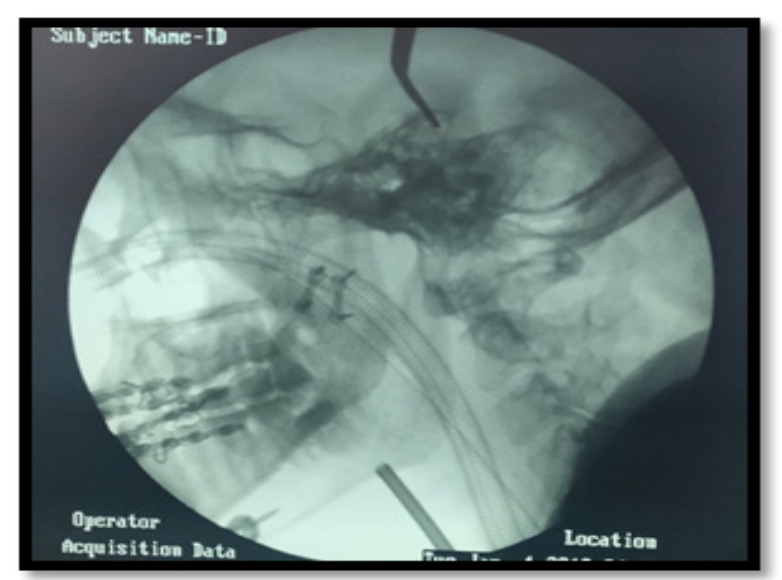

Figure 7 Intra operative use of $c$ arm guided fixation of angle fracture

Intraoperative radiographic assessment for reduction and fracture fixation was done using fluoroscopic guided c arm images (Figure 7,8) while temporarily releasing the maxilla-mandibular fixation. The intraoral vestibular incision was closed by absorbable Vicryl 3-0 after thorough irrigation of the intra-oral wound. The extraoral stab wound was closed by a single suture using Prolene 5-0.

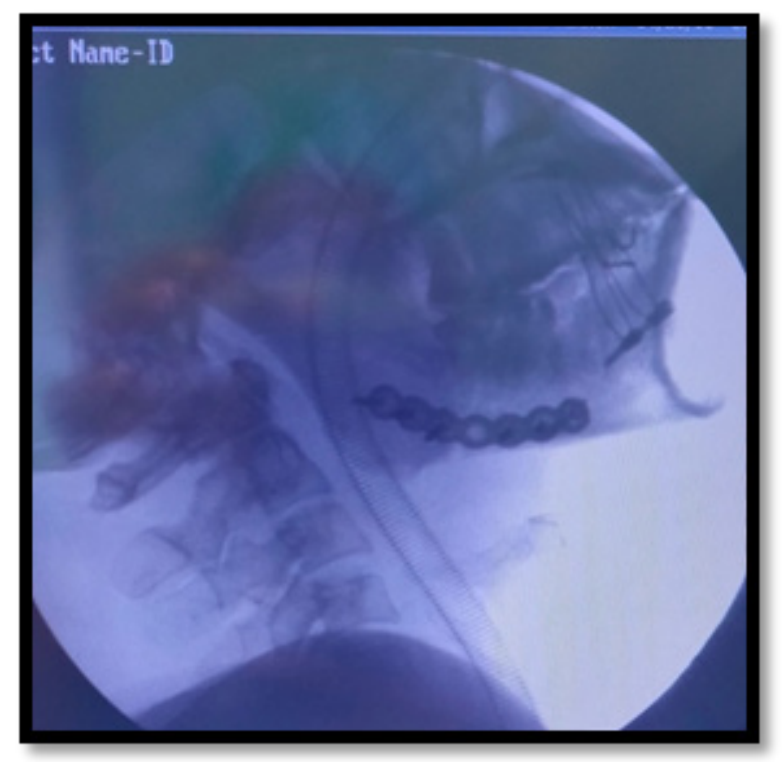

Figure 8 Intra operative use of $\mathrm{c}$ arm guided fixation of angle fracture

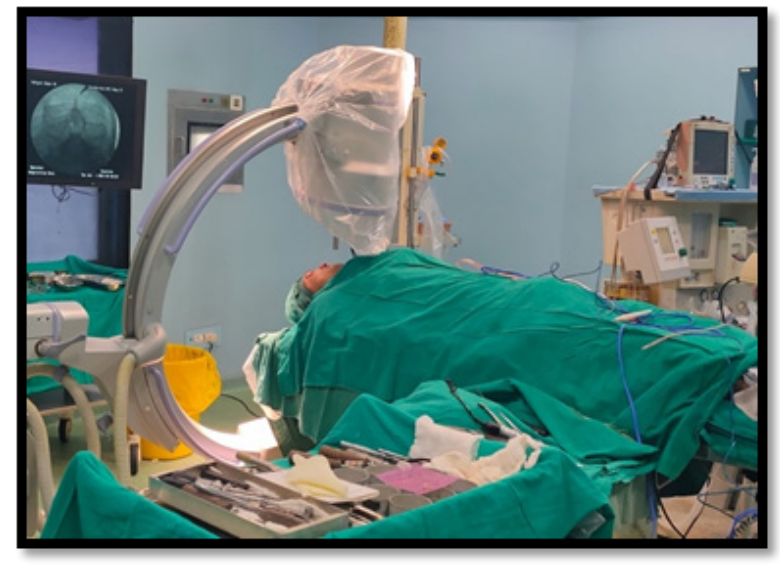

Figure 9 Intraoperative image using $C$ arm

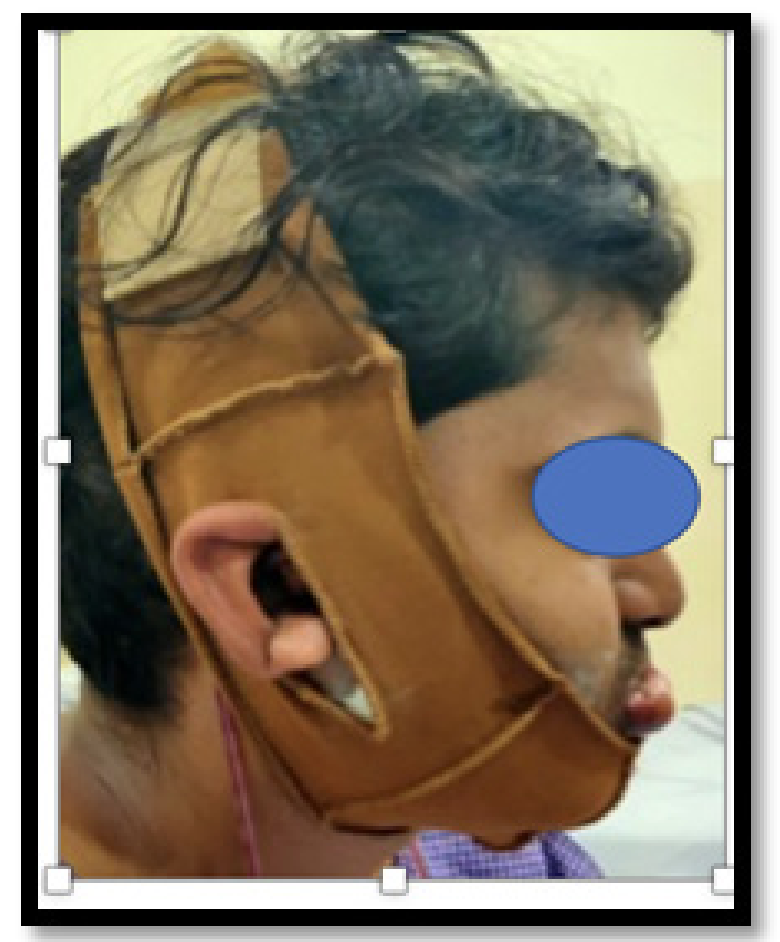

Figure 10 Chin strap applied on patient

Maxillomandibular fixation as well as the percutaneous K-wire were removed after satisfactory fixation and wound closure. A chin strap as shown in the (Figure 10) was advised to be worn by the patient for three weeks. This permitted soft semi-solid diet and better oral hygiene while providing support to the mandible reducing pain and oedema. Antimicrobials and NSAID'S was prescribed and oral hygiene maintenance was advised postoperatively for 5 to 7 days for all patients. Patient was advised for strict soft diet regime for three weeks. Patients follow-up was done regularly on interval of 3 weeks, 6 weeks, 3 
months, 6months post operatively.

Following evaluation was done.

1. Duration of the actual time of technique (operative time taken for the surgery was recorded from begin of the intraoral incision and ending with wound closure excluding the time to place MMF).

2. Complications such as (facial nerve injury, infection, hematoma, wound dehiscence ,presence of infection with sinus, malunion, non-union, trismus, masseter muscle hypertrophy, hypertrophic scar and occlusal disturbances).

\section{Statistical Analysis}

Data obtained were transferred to MS-excel sheet. The data were verified and analysed statistically using SPSS Statistics Version 21.0 (Armonk, NY: IBM Corp.) with confidence level set at $95 \%(P<0.05)$ to test for significance. Data were descriptively analysed.

\section{RESULTS}

Ten patients with mandibular angle and ramus fracture were included in this study. Their age ranged from 16 to 47 years with a mean age of 31.0 years which included nine male patients and one female patient. Seven patients had angle fracture

\section{Table 1: Age distribution and fracture type}

\begin{tabular}{|l|l|l|l|}
\hline SN & Age/Sex & $\begin{array}{l}\text { Type of } \\
\text { Fracture }\end{array}$ & $\begin{array}{l}\text { Operation } \\
\text { time (mins) }\end{array}$ \\
\hline 1 & $25 / \mathrm{M}$ & angle & 35.6 \\
\hline 2 & $26 / \mathrm{M}$ & ramus & 44.2 \\
\hline 3. & $44 / \mathrm{M}$ & angle & 36.7 \\
\hline 4. & $47 / \mathrm{M}$ & angle & 56.4 \\
\hline 5. & $22 / \mathrm{M}$ & $\begin{array}{l}\text { angle }+ \\
\text { p a r a } \\
\text { symphysis }\end{array}$ & 45.7 \\
\hline $\mathbf{6}$ & $18 / \mathrm{M}$ & ramus & 35.0 \\
\hline 7 & $23 / \mathrm{M}$ & angle & 34.6 \\
\hline 8 & $45 / \mathrm{M}$ & angle & 46.0 \\
\hline 9 & $21 / \mathrm{M}$ & angle & 34.9 \\
\hline 10 & $33 / \mathrm{F}$ & ramus & 46.2 \\
\hline
\end{tabular}

\begin{tabular}{|l|l|}
\hline Complications & No. of Patients \\
\hline Facial nerve injury & 0 \\
\hline Hematoma & 1 \\
\hline $\begin{array}{l}\text { Wound breakdown } \\
\text { Presence of infection with } \\
\text { sinus }\end{array}$ & 0 \\
\hline Malunion & 1 \\
\hline Non-union & 0 \\
\hline Trismus & 2 \\
\hline Masseter muscle hypertrophy & 0 \\
\hline Occlusal disturbances & 0 \\
\hline
\end{tabular}

at one side and three patients (30\%) had ramus fracture. The mean surgical duration was 41.5 minutes from incision to closure with fixation of angle fracture by one plate in 7 patients and two plates in 3 patients. (Table 1)

No patients were recorded as having an visible external scar. There was a soft tissue infection in 1 patient with sinus opening, and further wound debridement and closure was required. Trismus was observed in 2 patients with hematoma due to capillary bleeding, which was drained under local anaesthesia. Transient facial nerve palsy was not seen in any of patient (Table 2)

\section{DISCUSSION}

Discussion The angle and ramus are the most frequently involved site in patients with isolated mandibular fractures, which typically result from a direct external impact. The thinner cross-sectional area of this region of the mandible-and the presence of impacted third molars are thought to be primarily responsible for the high incidence of angle fractures. ${ }^{1}$ Ramus fractures are the second least common fractures with $3 \%$ incidence, coronoid fractures being the least common. $7,8,9$

In this small study of 10 patients, the incidence of mandibular angle-ramus fractures was seen in ages ranging from 16 to 47 years, with a mean age of 31 years. The peak incidence of fractures was seen in the second and third decades of life with a definite predilection in males $(n=9)$. Road traffic accidents was the most common etiological factor $(n=8$, $80 \%)$ followed by assault ( $n=2,20 \%)$.The study by Meisami et al. ${ }^{10}$, stated that the incidence of 
angle and ramus fractures was higher in the male population and was most common in the third decade of life.

Management techniques of angle and ramus fractures vary from closed reduction with MMF to open techniques via intraoral approach, external approach, combined intraoral with extra-oral approach. ${ }^{4,5}$ In extraoral approach often, there is a risk of injuring branches of the facial nerve and facial vessels which can lead to paraesthesia and massive haemorrhage if careful dissection is not done. They may also cause damage to the parotid gland/ duct causing post-operative complications such as salivary leak or sialocele. Other complication from extra-oral incision is the likelihood of unsightly and hypertrophic scars which might require revision surgeries. In contrast, the intra-oral approach has the advantage of no visible scars and no risk of injury to the facial nerve. But it gives limited and demanding access to the site of the fracture, particularly during insertion of screws leading to prolonged operation time and more considerable tissue damage. The extended surgical time comes with its share of post-operative complications.

Surgical time is defined as the time taken from incision and exposure of the fractured site to closure. The mean calculated duration of the present technique was found to be 41.5 minutes which is shorter than the time needed in standard percutaneous technique which was 64.9 to 93.5 minutes in previous studies by utilizing the traditional kit. 3,5 This reduced operation time could be attributed to use of $C$ arm guided images in this study which lead to better visualization of the fracture line, and served as a guide for placement of plates and screws. Understandably, in intraoral approach larger retractor and complicated manoeuvres could make the operation technically tricky. This finding contradicted studies in the literature that have shown increased surgical time with the percutaneous approach when compared to the transoral approach. ${ }^{3}$

The in vitro pilot study conducted by Kroon et al 11 stated that under certain conditions insufficient support is given by the miniplates such as that in cases of angle fractures reverse effects of tension and compression occur at the fracture site during loading close to the fracture, which effects apparently cannot be resisted by the fixation with only one miniplate at the position proposed by Champy. So in our study we proposed the fracture fixation by $2.5 \mathrm{~mm}$ recon plate at the inferior border if the displacement is minimal and two $2.0 \mathrm{~mm}$ miniplates in where considerable amount of displacement is present. In a similar study conducted by Siddiqui ${ }^{7}$ stated that single implant fixation technique had more complication as compared to two implant fixation technique. We in our study did not find ant statistical difference in any of the type of fixation technique.

In our study, none of the patients had postoperative occlusal disturbances which differed from the study conducted by Sugar et al. ${ }^{3}$, where the transoral (intra-oral) group had significantly more occlusal discrepancy than the trans buccal (extraoral) group. No patient presented with occlusal discrepancy at one months post-surgery. In our study, fluoroscopic guided C-arm images were used to visualize adequate reduction of fracture segment and meticulous internal fixation using mini plates and screws. This technique minimized the chances of malalignment and occlusal disharmony postoperatively.

Coming to incidences of facial nerve injuries, none of our patients reported with of facial nerve palsy with our limited extra-oral technique. This is in sharp contrast with other studies using the standard extraoral technique of submandibular incision, which is $4-5 \mathrm{~cm}$ in length, 1-2 finger breadths below the inferior border of the mandible. The rate of facial nerve injury after the traditional submandibular approach has been reported as being from $5.8 \%$ to $48.1 \%$ in study conducted by Al-Moraissi et al. ${ }^{4}$ whereas, the intra-oral approach produced a relatively lower incidence of facial nerve injury $0.72 \%$. Again, when the intraoral approach was supplemented with trans buccal (extra-oral) instrumentation, the facial nerve injury incidence increased to $2.7 \%$. When an endoscope is used, the frequency of facial nerve injury was even more with $4.2 \% .{ }^{4}$ The surgery in which no percutaneous instrumentation was used, employed intraoral placement of the endoscope, right-angled drills and screwdrivers. ${ }^{4}$

In the present technique, a stab incision permitting the use of a trocar and the head of a self-locking screwdriver was all that was necessary. Gentle retraction using thin-bladed retractors facilitated the placement of the plate and the screws under direct vision. The image intensifier confirmed the same. Besides, use of a percutaneous K-wire to maintain the reduction during the fixation of the fracture further facilitated the procedure significantly reducing the operating time. The stab 
incisions also reduced the risk of injury to any vital structures in the present technique.

There were no reported cases of dehiscence, or infection tissue mostly because of shorter operating time, less instrumentation and lesser tissue damage. One patient had a superficial abscess (a furuncle) near the surgical site, which was drained and the patient was put on antimicrobial therapy for one week and the wound healed without any further infection. All patients healed well with an invisible scar.

So, the described percutaneous approach to mandibular angle and ramus fracture could be used effectively with minimal cost using readily available tools permitting perpendicular relations between the plate and inserted screws under fluoroscopic guidance of $\mathrm{C}$-arm for intraoperative Imaging. There was no need for unique instrumentation as in via intra-oral approach where angled motor and screwdriver is required for drilling and insertion of screws. A further controlled trial is needed on an extensive series of patients consisting of both control and study groups.

\section{CONCLUSION}

The use of a limited percutaneous approach showed a fewer complications and post-operative occlusal stability. Even though the series is minimal, it is well conceivable and can be easily learnt. The technique definitely reduces the difficulty of operating through the intra-oral approach alone. At the same time, ugly scarring and injury to the facial nerve and parotid tissue commonly associated with lone external approach is obviated. The same combined approach could be effective for open reduction and internal fixation of sub-condylar fractures as well.

\section{REFERENCES}

1. Pickrell BB, Serebrakian AT, Maricevich RS. Mandible Fractures. Semin Plast Surg. 2017;31(2):100-107. https://doi.org/10.1055/s-0037-1601374 [PubMed] [GoogleScholar]

2. Afrooz PN, Bykowski MR, James IB, Daniali LN, Clavijo-Alvarez JA. The epidemiology of mandibular fractures in the United States, part 1: a review of 13,142 cases from the US National Trauma Data Bank. J Oral Maxillofac Surg. 2015;73(12):2361-2366.https://doi. org/10.1016/j.joms.2015.04.032 [GoogleScholar] [PubMed] [FullText]

3. Sugar AW, Gibbons AJ, Patton DW, Silvester KC, Hodder SC, Gray M, et al. A randomized controlled trial comparing fixation of mandibular angle fractures with a single miniplate placed either transbuccally and intra-orally, or intra-orally alone. Int J Oral Maxillofac Surg. 2009;38:241-245. https://doi.org/10.1016/j. ijom.2008.11.001 [PubMed] [GoogleScholar] [FullText]

4. Al-Moraissi E. A, Louvrier, A, Colletti G, Wolford L. M, Biglioli F, Ragaey M, ... Ellis E. Does the surgical approach for treating mandibular condylar fractures affect the rate of seventh cranial nerve injuries? A systematic review and meta-analysis based on a new classification for surgical approaches. Journal of Cranio-MaxillofacialSurgery $\quad$ 2018;46(3):398-412. https://doi.org/10.1016/j/jems.2017.10.024 [PubMed] [GoogleScholar] [FullText]

5. Sudhakar GVS, Rajasekhar G, Dhanala S, et al. Comparison of management of mandibular angle fractures by three approaches. J Maxillofac Oral Surg 2015;14:979-985.https://doi:10.1007/s12663-0150779-0 [PubMed] [GoogleScholar]

6. Gear AJ, Apasova E, Schmitz JP, Schubert W. Treatment modalities for mandibular angle fractures. J Oral Maxillofac Surg. 2005;63:655663. https://doi.org/10.1016/j.joms.2004.02.016 [PubMed] [GoogleScholar] [CrossRef] [FullText]

7. Siddiqui A, Markose G, Moos KF, et al. One miniplate versus two in the management of mandibular angle fractures; a prospective randomized study. Br J Oral MaxillofacSurg 2007;45:233-235. https:// doi.org/10.1016/j.bjoms.2006.08.016 [PubMed] [GoogleScholar]

8. Jadhav A, Mundada B, Deshmukh R, Bhutekar U, Kala A, Waghwani K, Mishra A. Mandibular ramus fracture: an overview of rare anatomical subsite. Plastic surgery international. 2015;2015:954314. https://doi.org/10.1155/2015/954314 [PubMed] [Full Text] [GoogleScholar]

9. Kale TP, Motimath A, Korlepara Y, Kotrashetti SM. Transbuccal Approach for Management of Linear Ramus Fractures of Mandible: A Clinical Technique. World J Dent 2018;9(6):517-522. https://doi. org/10.5005/jp-journals-10015-1590 [Weblink]

10. Meisami T, Sojat A, Sàndor GK, Lawrence HP, Clokie CM. Impacted third molars and risk of angle fracture. Int J Oral Maxillofac Surg. 2002;31:140-144. https://doi.org/10.1054/ijom.2001.0215 [PubMed] [GoogleScholar] [CrossRef] [FullText]

11. Kroon FH, Mathisson M, Cordey JR, Rahn B A. The use of miniplates in mandibular fractures. Journal of CranioMaxillofacial Surgery, 1991;19(5): 199-204. https://doi. org/10.1016/s1010-5182(05)80547-5 [Pubmed] 